\title{
Robust induction of $B$ cell and $T$ cell responses by a third dose of inactivated SARS-CoV-2 vaccine
}

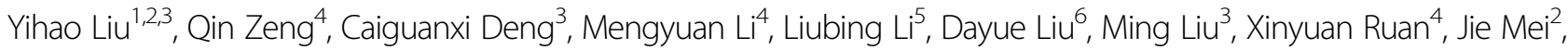

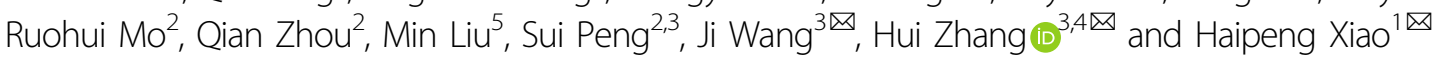

\begin{abstract}
SARS-CoV-2 inactivated vaccines have shown remarkable efficacy in clinical trials, especially in reducing severe illness and casualty. However, the waning of humoral immunity over time has raised concern over the durability of immune memory following vaccination. Thus, we conducted a nonrandomized trial among the healthcare workers (HCWs) to investigate the long-term sustainability of SARS-CoV-2-specific B cells and T cells stimulated by inactivated vaccines and the potential need for a third booster dose. Although neutralizing antibodies elicited by the standard two-dose vaccination schedule dropped from a peak of 29.3 arbitrary units $(\mathrm{AU}) / \mathrm{mL}$ to $8.8 \mathrm{AU} / \mathrm{mL} 5$ months after the second vaccination, spike-specific memory $B$ and $T$ cells were still detectable, forming the basis for a quick recall response. As expected, the faded humoral immune response was vigorously elevated to $63.6 \mathrm{AU} / \mathrm{mL}$ by 7.2 folds 1 week after the third dose along with abundant spike-specific circulating follicular helper T cells in parallel. Meanwhile, spike-specific $\mathrm{CD}^{+}$and $\mathrm{CD} 8^{+} \mathrm{T}$ cells were also robustly elevated by 5.9 and 2.7 folds respectively. Robust expansion of memory pools by the third dose potentiated greater durability of protective immune responses. Another key finding in this trial was that HCWs with low serological response to two doses were not truly "non-responders" but fully equipped with immune memory that could be quickly recalled by a third dose even 5 months after the second vaccination.

Collectively, these data provide insights into the generation of long-term immunological memory by the inactivated vaccine, which could be rapidly recalled and further boosted by a third dose.
\end{abstract}

\section{Introduction}

The coronavirus disease 2019 (COVID-19), caused by the severe acute respiratory syndrome coronavirus 2 (SARS-CoV-2), continues to spread across the globe currently $^{1,2}$. The pandemic has brought profound casualties of human lives and socioeconomic issues. The establishment of herd immunity by vaccination represents the most cost-effective strategy to prevent COVID-19.

Correspondence: Ji Wang (wangj683@mail.sysu.edu.cn) or Hui Zhang (zhangh656@mail.sysu.edu.cn) or Haipeng Xiao (xiaohp@mail.sysu. edu.cn)

${ }^{1}$ Department of Endocrinology, The First Affiliated Hospital of Sun Yat-sen University, Guangzhou, Guangdong, China

${ }^{2}$ Clinical Trials Unit, The First Affiliated Hospital of Sun Yat-sen University, Guangzhou, Guangdong, China

Full list of author information is available at the end of the article These authors contributed equally: Yihao Liu, Qin Zeng, Caiguanxi Deng, Mengyuan Li, Liubing Li, Dayue Liu
The rapid spreading of COVID-19 has urged the governments to authorize the emergent use of vaccines against SARS-CoV-2 $2^{3-5}$.

The presence of neutralizing antibodies (NAbs) against SARS-CoV-2 is an indicator of protective immunity after vaccination or infection ${ }^{6,7}$. NAbs capable of blocking the interaction between the spike protein and its receptor angiotensin-converting enzyme 2 (ACE2) are particularly important for protection from COVID-19 ${ }^{8}$. Therefore, inducing potent NAbs and long-lasting memory B cells is the primary goal of SARS-CoV-2 vaccines. Two doses of mRNA or inactivated vaccines are capable of inducing potent neutralizing antibody responses ${ }^{3,9,10}$. Our previous study further demonstrated that inactivated vaccines elicited SARS-CoV-2-specific memory B cells ${ }^{11}$, which are important for a rapid and robust recall of protective responses against viral infection. However, little is known

\section{(c) The Author(s) 2022}

(c) (i) Open Access This article is licensed under a Creative Commons Attribution 4.0 International License, which permits use, sharing, adaptation, distribution and reproduction c. in any medium or format, as long as you give appropriate credit to the original author(s) and the source, provide a link to the Creative Commons license, and indicate if changes were made. The images or other third party material in this article are included in the article's Creative Commons license, unless indicated otherwise in a credit line to the material. If material is not included in the article's Creative Commons license and your intended use is not permitted by statutory regulation or exceeds the permitted use, you will need to obtain permission directly from the copyright holder. To view a copy of this license, visit http://creativecommons.org/licenses/by/4.0/. 
how long these immune responses could sustain. A rapid decline of NAbs has been observed among infected healthcare workers $(\mathrm{HCWs})^{12}$. NAbs also waned overtime after the second dose of BNT162b2 or ChAdOx $1^{13}$, indicating weakened protection for SARS-CoV-2 infection. In addition, the rapid emergence of novel SARS$\mathrm{CoV}-2$ variants of concern (VOCs) dampens the efficacy of SARS-CoV-2 vaccines, since vaccine-induced antibodies were less effective in neutralizing some emerging $\mathrm{VOCs}^{14}$. Moreover, cross-reactive antibodies against VOCs decayed even faster than antibodies against wildtype (WT) strain $^{15}$.

Besides humoral immune responses, $\mathrm{T}$ cells also play a pivotal role in coordinating the adaptive immune responses and as effectors against viral infection. In some cases, patients with inherited or treatment-induced B cell deficiency were able to recover from COVID-19 ${ }^{16,17}$, suggesting a potential role of cellular responses in fighting against SARS-CoV-2 infection. Induction of $\mathrm{CD}^{+} \mathrm{T}$ cell responses was documented in both SARS-CoV-2 infection and vaccination ${ }^{18,19}$. On the other hand, rapid induction of $\mathrm{CD}^{+} \mathrm{T}$ cells is associated with coordinated humoral and cellular response to a SARS-CoV-2 mRNA vaccine ${ }^{20}$. SARS-CoV-2-specific circulating $\mathrm{T}$ follicular helper cells (cTFH) cells, whose counterparts in lymph nodes reinforce $\mathrm{B}$ cells and humoral responses ${ }^{21}$, correlated with $\mathrm{Nab}$ levels in convalescent COVID-19 patients $^{22,23}$.

Nevertheless, $\mathrm{T}$ cell responses induced by inactivated vaccines are much less well characterized than humoral immunity. One previous study revealed that the inactivated vaccine could elicit $\mathrm{T}$ cells response after two doses of vaccination ${ }^{24}$, but the phenotype and sustainability of antigen-specific $\mathrm{CD} 4^{+}$and $\mathrm{CD} 8^{+} \mathrm{T}$ cells remained unclear yet.

In this study, we sought to investigate the sustainability of immune memory stimulated by the inactivated vaccine and to profile humoral and cellular responses to the third dose among HCWs. Although NAbs declined substantially, SARS-CoV-2-specific memory B, $\mathrm{CD} 4^{+}$, and $\mathrm{CD} 8^{+} \mathrm{T}$ cells persisted in the peripheral blood 5 months after the second vaccination, even in participants who were seronegative after receiving two doses of the inactivated vaccines. The third vaccination robustly recalled both humoral and cellular immune responses in all participants.

\section{Results}

NAb response is enhanced by a third dose of inactivated SARS-CoV-2 vaccine BBIBP-CorV

We have previously conducted a nonrandomized trial and recruited HCWs from a prospective cohort, demonstrating the impact of the circadian rhythm on the immune response induced by a primary two-dose series of the inactivated SARS-CoV-2 vaccine (BBIBP-CorV, Sinopharm, Beijing) ${ }^{11}$. Fifty HCWs from this cohort were volunteered to participate in the current nonrandomized trial to investigate the duration of the primary vaccination regimen and potential benefits of a third dose, given 5 months after the second dose (Fig. 1a). No severe side effects related to vaccination were recorded during the trial (Supplementary Table S1).

Blood samples were collected from multiple time points before and after each dose and NAbs targeting receptorbinding domain (RBD) were measured by Chemiluminescent immunoassay ${ }^{25}$. The mean serum concentration of NAbs dropped by $70 \%$ from day (d) 56 (1-month post the second dose) to d180 (5 months after the second dose) (Fig. 1b). Intriguingly, NAbs maintained a significantly higher level in the morning vaccination group than that in the afternoon group on d180 (Fig. 1d).

Although serum NAbs in $72 \%$ of participates (36/50) dropped below the threshold (10 arbitrary units $(\mathrm{AU}) / \mathrm{mL})$ on $\mathrm{d} 180$, serological responses could be rapidly recalled to an unprecedented level within 1 week after the third dose. The mean concentration of NAbs was increased by 7.2 folds from $8.8 \mathrm{AU} / \mathrm{mL}$ on d180 to $63.6 \mathrm{AU} / \mathrm{mL}$ on d187, peaking at $92.3 \mathrm{AU} / \mathrm{mL} 2$ weeks after the booster (Fig. 1c). As the primary vaccination series ${ }^{11}$, the circadian rhythm also governed the outcome of the third dose, albeit only at the early stage. Significantly higher levels of NAbs were observed in the morning group after the third dose on d187 (Fig. 1d). However, the difference between the morning and the afternoon groups gradually diminished over time (Fig. 1d). Moreover, we did not observe any difference in NAb levels between females and males (Fig. 1e).

Pseudovirus neutralizing assays were next applied to confirm the elevation of serum NAbs against WT SARS$\mathrm{CoV}-2$ and VOCs by the third dose. Consistent with the results of Chemiluminescent immunoassay, half-maximal inhibitory dilutions $\left(\mathrm{ID}_{50}\right)$ against WT was greatly boosted (Fig. 1f). Encouragingly, the third dose not only elevated the NAbs against WT, but also strengthened a cross-protective immune response. The mean serum $\mathrm{ID}_{50}$ against B.1.167.2 Delta variant was increased tenfold from d180 to d194 (Fig. 1g). In pseudovirus assay, a significantly higher level of NAbs against both WT and B.1.167.2 could still be observed in the morning vaccination participants (Fig. 1h, i).

One potential advantage of inactivated vaccines over other vaccine types is that they comprise all viral structural proteins which may induce a broader spectrum of immunity in addition to NAbs against RBD. To profile the antibody spectrum induced by BBIBP-CorV, serum IgG against major SARS-CoV-2 structural proteins and their subdomains, including S1/S2 subunits, RBD, $\mathrm{N}$ terminal domain (NTD) of spike protein, nucleocapsid, and small envelope protein, were measured by indirect enzymelinked immunosorbent assay (ELISA) before and after the third dose. As expected, BBIBP-CorV successfully elicited antibodies against all structural proteins and subdomains 
a

AM vaccination
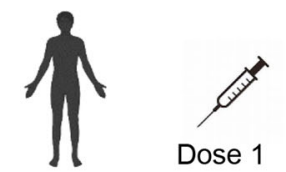

PM vaccination<smiles>C=COCC</smiles>

c

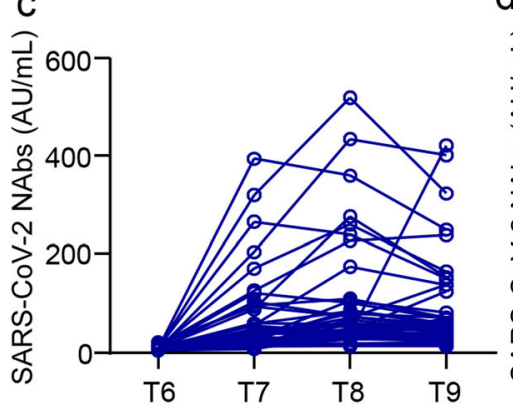

f

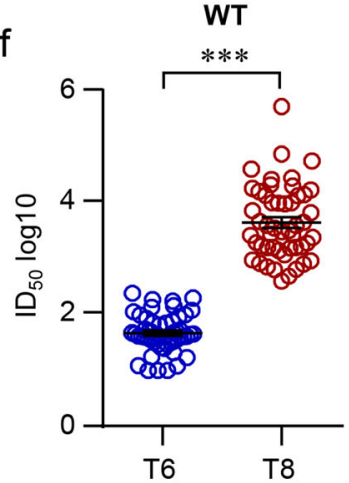

d

g
BBIBP-CorV
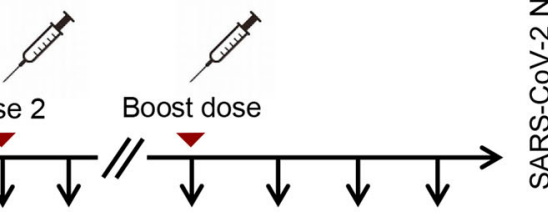

T6 T7 T8 T9

d180 d187 d194 d201

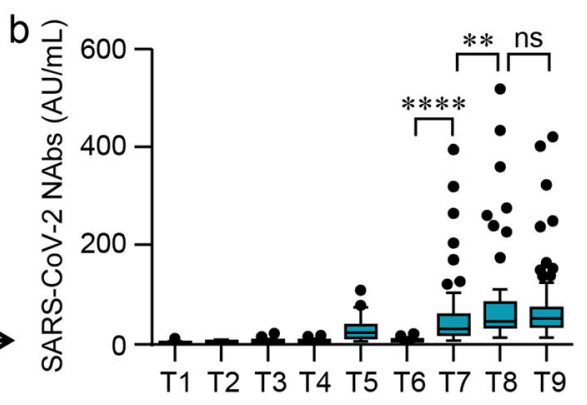

e
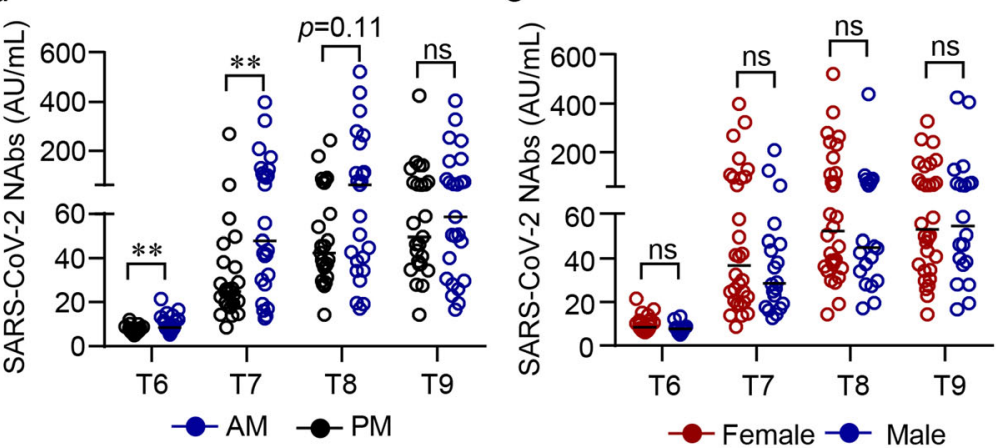

B.1.167.2

B.1.167.2

$\mathrm{h}$
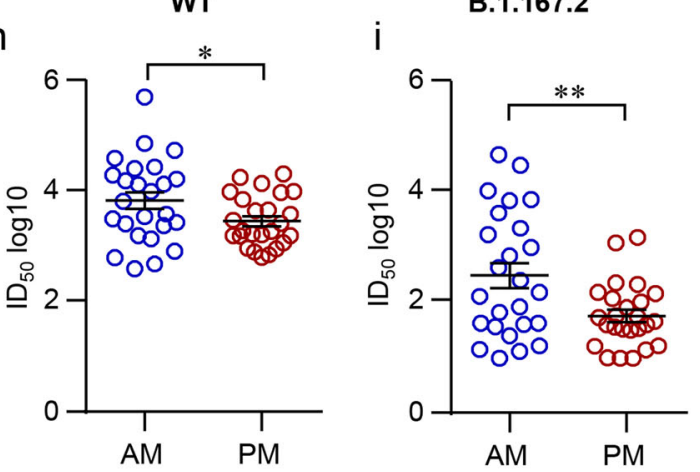

Fig. 1 Humoral responses induced by a third dose of inactivated SARS-CoV-2 vaccine BBIBP-CorV. a Protocol of the prospective cohort and the nonrandomized trial. Healthcare workers (HCWs) were recruited from a perspective cohort who received two doses of an inactivated vaccine either in the morning ( $\mathrm{AM}, n=25)$ or afternoon (PM, $n=25$ ) on day (d) 0 and $\mathrm{d} 28$. They were assigned to morning or afternoon vaccination to receive a third dose of the inactivated vaccine on day 180 according to their previous vaccinating time. Blood samples were collected on different time points d0 (T1), d14 (T2), d21 (T3), d28 (T4), d56 (T5), d180 (T6), d187 (T7), d194 (T8), and d208 (T9). b-e Neutralizing antibodies (NAbs) against SARS-CoV-2 in the serum of each volunteer was measured by Chemifluorescence Assay longitudinally. $\mathbf{b}$ The concentration of NAbs in the sera at different time points was summarized and shown in the box plot. c The longitudinal changes of NAbs in the sera before and after the third dose of vaccination. $\mathbf{d}$ NAbs in the sera from the morning or afternoon group at different time points. e NAb concentrations in the sera of female or male. Medians of the data were shown. $\mathbf{f}, \mathbf{g}$ Neutralizing activities of sera against SARS-CoV-2 were measured by pseudovirus neutralizing assay. Halfmaximal inhibitory dilutions (ID $\mathrm{D}_{50}$ ) of sera from T6 and T8 against SARS-CoV-2 WT and Delta variant (B.1.167.2) were summarized. $\mathbf{h}$, $\mathbf{i}$ Comparison of neutralizing activities between the morning and afternoon group on T8. Comparisons were done by Wilcoxon rank-sum test in $\mathbf{b}-\mathbf{e}$ or Student's ttest in $\mathbf{f}-\mathbf{h}$. ${ }^{* *} P<0.01,{ }^{* * *} P<0.0001 ;$ ns, not significant.

tested (Supplementary Fig. S1). Notably, we found that all vaccinees were equipped with a high titer of anti-envelope IgG which has not been reported in a vaccine study elsewhere and was hardly induced even during natural SARS-CoV-2 infection ${ }^{26}$. Interestingly, the third dose did not elevate antibody responses against all tested structural 
proteins or subdomains evenly, but profoundly augment the immune response against the S1 domain of spike protein which comprises NTD and RBD subdomains (Supplementary Fig. S1).

\section{SARS-CoV-2-specific memory B cell response is robustly induced by a third dose of inactivated vaccine}

The rapid and robust recall of humoral immune responses by the third vaccination indicated that the primary two-dose vaccination regimen has established a sustained immune memory. We explored the presence of antigen-specific memory B cells before and after the third dose by flow cytometry.

Total B cell populations were first characterized by flow cytometry (Supplementary Fig. S2). Only mild changes in $\operatorname{IgD}^{+}, \operatorname{IgM}^{+}, \operatorname{IgA}^{+}$, or $\operatorname{IgD}^{-} \mathrm{CD} 27^{-}$B cells were found before and after the booster, whereas the percentage of total and naïve B cells were not affected (Supplementary Fig. S3), consistent with a good safety profile of the third dose (Supplementary Table S1).

Next, antigen-specific B cell populations were investigated. Spike- and RBD-specific memory B cells could be detected at 4 weeks (d56) and 5 months (d180) after the second dose, revealing that memory $\mathrm{B}$ cells persisted despite a decreasing trend over a 5-month time frame between second and third immunization (Fig. 2a, c). The third dose increased the percentages of spike- and RBDspecific memory B cells by 1.7 and 2.0 folds respectively from d180 to d187, resulting in a significantly larger memory pool on d187 than that on d56 (Fig. 2b, d). The majority of these antigen-specific memory $B$ cells could be classified into $\operatorname{IgG}^{+}$or $\operatorname{IgM}^{+}$B cells, while a minor population of them was $\operatorname{IgA}^{+} \mathrm{B}$ cells (Fig. 2e, f).

The capability of these spikes- or RBD-specific memory B cells in secreting antibodies upon the antigen stimulation was further confirmed by the B cell enzyme-linked immunospot (ELISpot) assay. The third dose boosted spike- or RBD-responsive, IgG-secreting $B$ cells from eight spotforming units (s.f.u.) $/ 10^{6}$ peripheral blood mononuclear cells (PBMCs) to 17 s.f.u. $/ 10^{6} \mathrm{PBMCs}$ or 4 s.f.u. $/ 10^{6}$ PBMCs to 10.7 s.f.u. $/ 10^{6}$ PBMCs respectively (Fig. $2 \mathrm{~g}-\mathrm{i}$ ). These results demonstrated that the primary two-dose vaccination regimen had equipped vaccinees with long-lasting memory B cells that could be immediately recalled and further expanded by a third dose of the inactivated vaccine.

\section{The cellular immune response is boosted by a third dose of inactivated SARS-CoV-2 vaccine}

Besides humoral immune responses, the cellular arm of immunity confers another layer of protection, which may be particularly crucial when B cell epitopes mutate rapidly and continuously. Therefore, antigen-specific $\mathrm{T}$ cells induced by the primary vaccination regimen and the third dose booster were next investigated. Blood samples collected on d180 and d187 were stimulated by the spike peptide pool and IFN $\gamma$ secreting cells were quantified by ELISpot. Surprisingly, antigen-responsive IFN $\gamma$-secreting $\mathrm{T}$ cells were readily detected in all vaccinees even 5 months after the second dose, though a lower amount was found in some participants (Fig. 3a, b). As IgG-secreting B cells, IFNy-secreting T cell responses were also enhanced by 2.3 folds after the third dose (Fig. 3a, b).

Next, SARS-CoV-2-specific $\mathrm{CD}^{+}$were identified by activation-induced markers (AIM) $\mathrm{T}$ cell assay, based on the previous observation that antigen-specific $\mathrm{CD}^{+} \mathrm{T}$ cells could be identified by $\mathrm{CD}^{+} 9^{+} 4-1 \mathrm{BB}^{+}$after the peptide pool stimulation ${ }^{27}$. In line with ELISpot, $\mathrm{CD}^{+} \mathrm{CD}^{+} 9^{+} 4-1 \mathrm{BB}^{+}$ $\mathrm{T}$ cells were seen on d180, and further elevated by 2.7 folds following a booster shot (Fig. 3c, d). Subsequent analysis on phenotypic markers revealed that the majority of the SARSCoV-2-specific $\mathrm{CD}^{+}{ }^{+} \mathrm{T}$ cells were CD45RA ${ }^{+} \mathrm{CCR}^{-}$terminally differentiated effector memory cells $\left(\mathrm{T}_{\mathrm{EMRA}}\right)$, whereas $\mathrm{CD} 4 \mathrm{RA}^{-} \mathrm{CCR} 7^{-}$effector memory $\mathrm{T}$ cells $\left(\mathrm{T}_{\mathrm{EM}}\right)$ accounted for only one-fourth of the total antigen-specific $\mathrm{CD} 8^{+}$ $\mathrm{T}$ cells (Fig. 3e), similar to that from recovered COVID-19 patients ${ }^{27}$. The subsets of total $\mathrm{CD}^{+} \mathrm{T}$ cells were not affected (Supplementary Figs. S4 and S5). The presence of antigen-specific $\mathrm{CD}^{+} \mathrm{T}$ cells was further confirmed by conventional intracellular cytokine staining (ICS) assay, in which PBMCs were stimulated with spike peptide pool and IFN $\gamma$ expression in $\mathrm{CD}^{+} \mathrm{T}$ cells was measured by flow cytometry. $\mathrm{CD}^{+}{ }^{+} \mathrm{FN}^{+}{ }^{+} \mathrm{T}$ cells were detected on $\mathrm{d} 56$, and decreased over time till the third vaccination, which elevated IFN $\gamma$-expressing $\mathrm{CD}^{+} \mathrm{T}$ cells to a greater extent when compared to that on d56 (Fig. 3h, i).

SARS-CoV-2-specific CD4 ${ }^{+} \mathrm{T}$ cells were identified by activation markers OX40 and 4-1BB after the peptide stimulation ${ }^{27} . \mathrm{CD}^{+}{ }^{+} \mathrm{OX} 40^{+} 4-1 \mathrm{BB}^{+} \mathrm{T}$ cells were detected at a low level on d180. The third dose induced the expansion of these $\mathrm{CD}^{+} \mathrm{T}$ cells by 5.9 folds within 1 week (Fig. 4a, b). Phenotypic analysis showed that the majority of the SARSCoV-2-specific $\mathrm{CD}^{+} \mathrm{T}$ cells were $\mathrm{CD}^{+} 5 \mathrm{RA}^{-} \mathrm{CCR} 7^{+} \mathrm{T}_{\mathrm{CM}}$ and CD45RA ${ }^{-} C C R 7^{-} \mathrm{T}_{\mathrm{EM}}$, different from that of SARSCoV-2-specific $\mathrm{CD}^{+}{ }^{+} \mathrm{T}$ cells (Fig. 4c). Among SARS-CoV2-specific $\mathrm{CD}^{+}{ }^{+} \mathrm{T}$ cells, $57.7 \%$ of the cells were CXCR5 ${ }^{+}$ cTFH cells (Fig. $4 \mathrm{~d}-\mathrm{g}$ ). Among total $\mathrm{CD} 4^{+} \mathrm{T}$ cells, we observed the slightly decreased $\mathrm{T}_{\mathrm{N}}$ cells, with increased $\mathrm{T}_{\mathrm{EM}}$ and $\mathrm{T}_{\mathrm{CM}}$ cells in the peripheral blood (Supplementary Figs. $\mathrm{S} 4$ and S5). Again, SARS-CoV-2-specific $\mathrm{CD} 4^{+} \mathrm{T}$ cells were confirmed by ICS assay. $\mathrm{CD}^{+} \mathrm{IFN}^{+}{ }^{+} \mathrm{T}$ cells showed a similar trend as that of $\mathrm{CD}^{+} \mathrm{IFN} \gamma^{+} \mathrm{T}$ cells. As expected, the drop of antigen-specific $\mathrm{CD} 4^{+} \mathrm{T}$ cells was reversed by the third dose (Fig. 4h, i).

Besides $\mathrm{CD} 4^{+}$and $\mathrm{CD} 8^{+} \mathrm{T}$ cells, we also found a unique population, SARS-CoV-2-specific $\mathrm{CD} 3^{+} \mathrm{CD} 4^{-} \mathrm{CD} 8^{-} \mathrm{T}$ cells persisted 5 months after the second immunization with inactivated vaccines, which were further elevated by the third vaccination (Fig. 3f, g). 
a

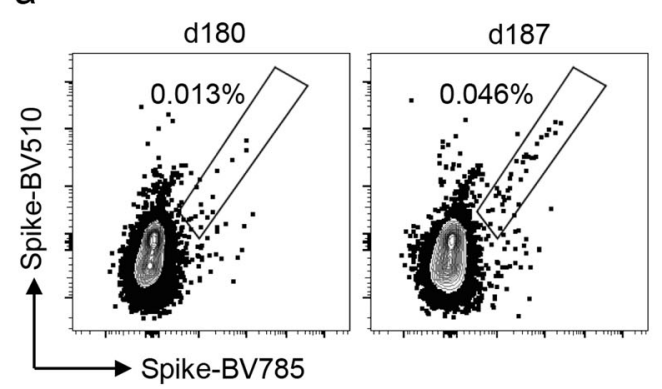

C

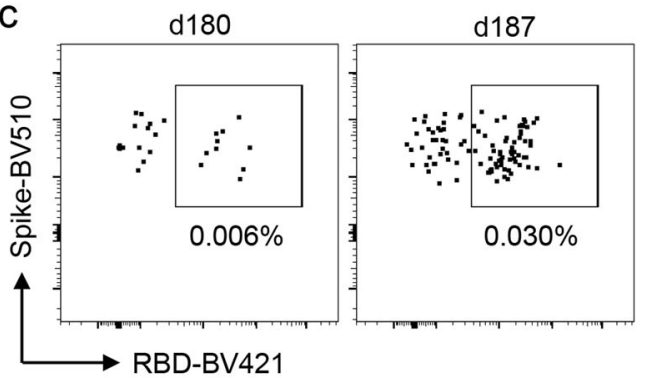

b
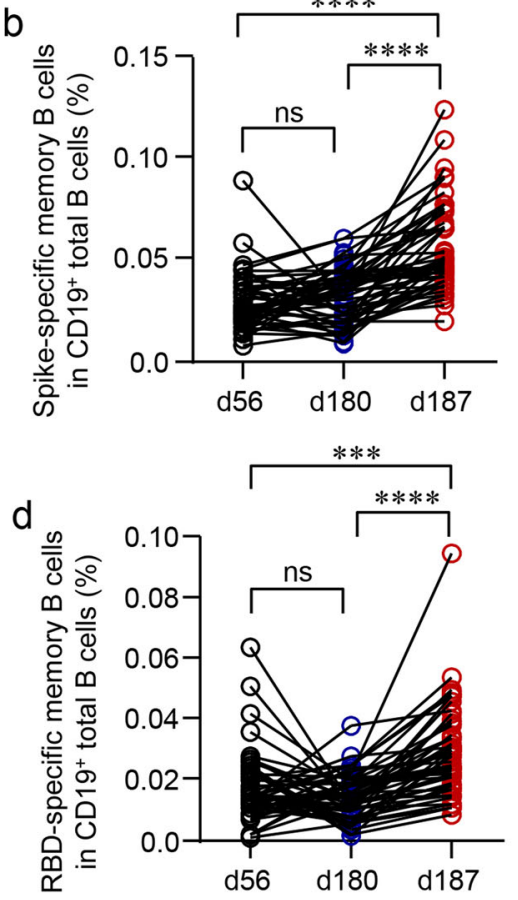

e
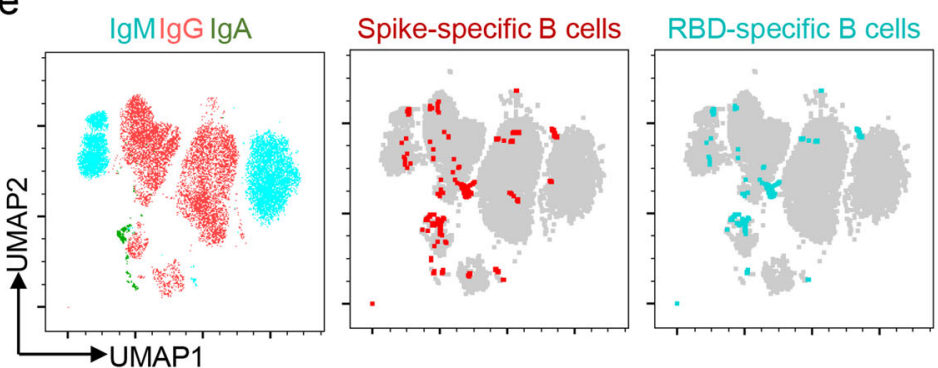

f

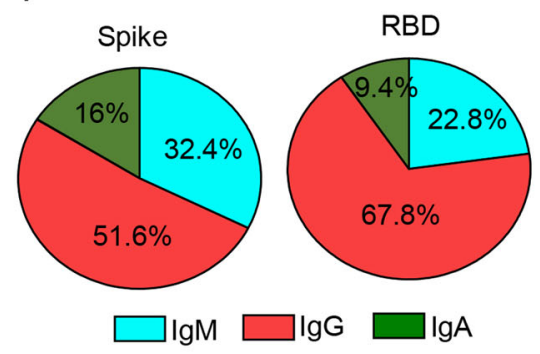

g
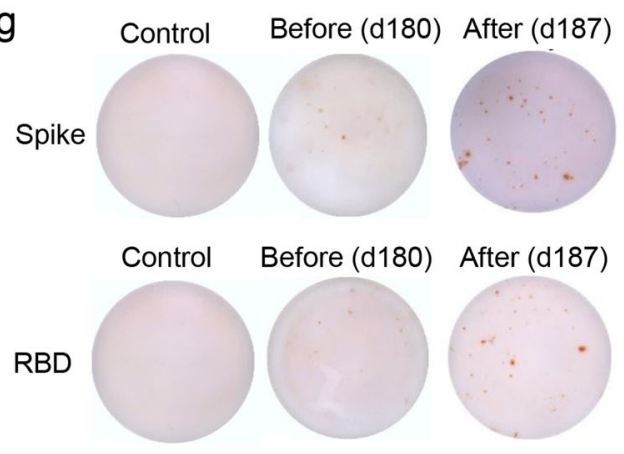

h
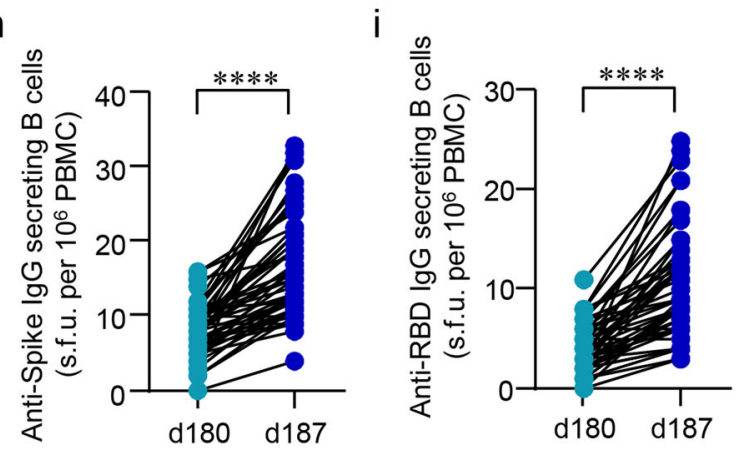

Fig. 2 SARS-CoV-2-specific memory B cell after a third dose of inactivated vaccine. Recombinant spike or receptor-binding domain (RBD) proteins were used to label SARS-CoV-2-specific BCR. Data were acquired by flow cytometry. a, c Representative FACS plots for the spike- or RBDspecific BCR were shown. $\mathbf{b}$, $\mathbf{d}$ Longitudinal changes of spike- or RBD-specific memory B cells were summarized. e $\lg G^{+}, \lg A^{+}$, and $\lg M^{+} B$ cells were measured by flow cytometry. The UMAP plot demonstrated the distribution of spike- and RBD-specific memory $B$ cells in $\lg G^{+}, \lg A^{+}, a^{2}$ lg $\lg { }^{+} B$ cells. $\mathbf{f}$ Mean percentages of each BCR subtype in spike- and RBD-specific B cells were summarized. $\mathbf{g}$ Spike- or RBD-specific lgG-secreting B cells were measured by ELISpot after incubating PBMCs in spike- or RBD-coated plates for $18 \mathrm{~h}$. Representative ELISpot images were shown. $\mathbf{h}$, i Numbers of Spike- or RBD-specific lgG-secreting B cells per $10^{6}$ PBMCs were expressed as spot-forming units (s.f.u.) and summarized. Comparisons were done by one-way ANOVA corrected for multiple comparisons in $\mathbf{b}$, $\mathbf{d}$ and Student's paired $t$-test in $\mathbf{h}, \mathbf{i}$. ${ }^{* * *} P<0.001$, ${ }^{* * * *} P<0.0001$; ns, not significant. 
a

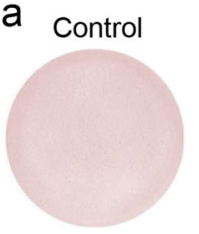

d180

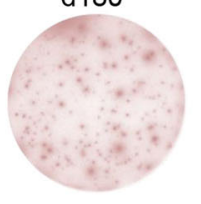

d187
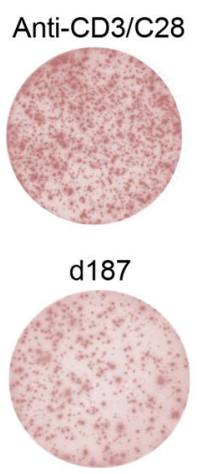

b

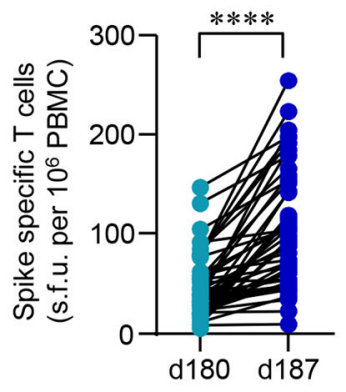

C

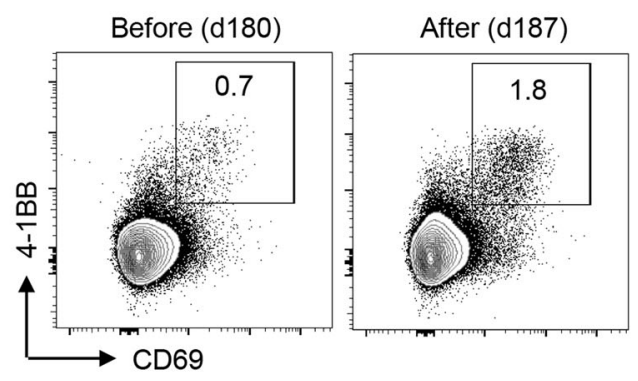

d

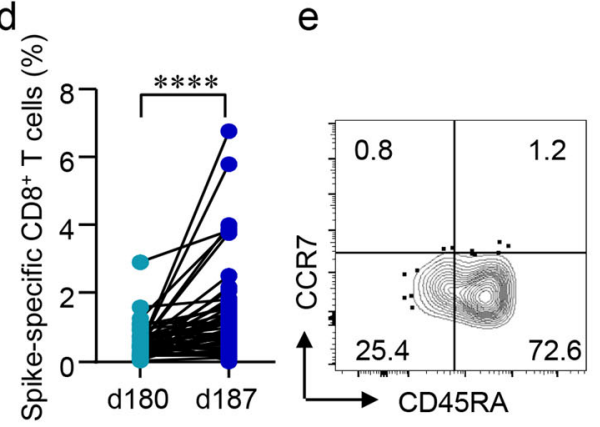

h

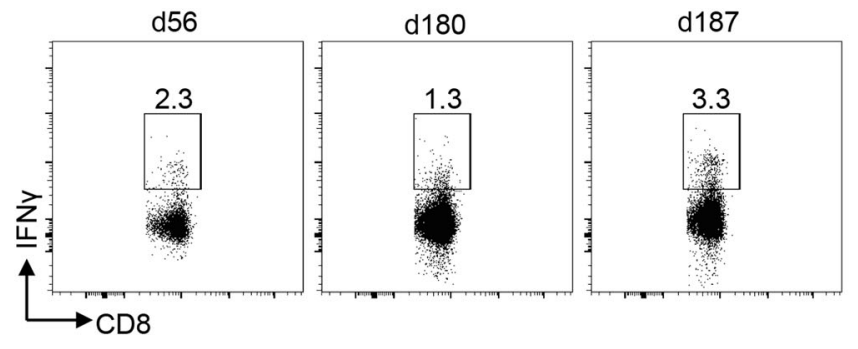

f

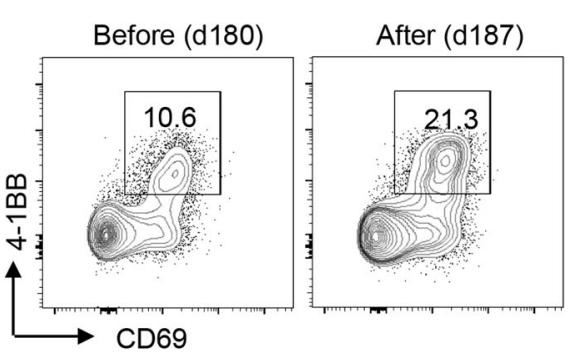

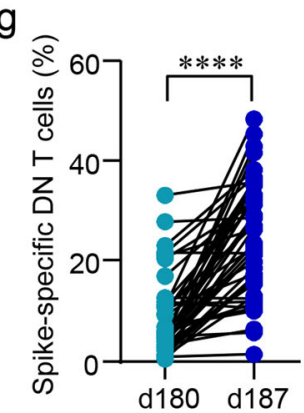

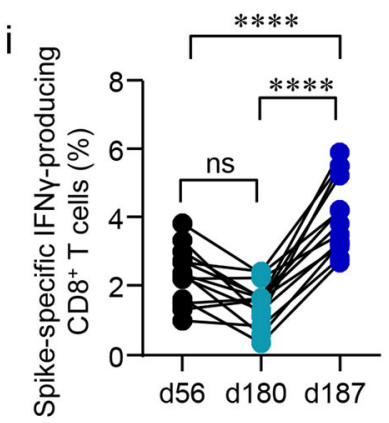

Fig. 3 Cellular responses induced by a third dose of inactivated SARS-CoV-2 vaccine. a PBMCs were stimulated with or without the spike peptide pool $(2 \mathrm{\mu g} / \mathrm{mL})$. Anti-CD3/CD28 dynabeads served as a positive control. IFNy-producing T cells were detected by ELISpot after $24 \mathrm{~h}$ incubation. Representative images of ELISpot wells were shown. $\mathbf{b}$ The number of IFNy-producing T cells was quantified as the spot-forming units (s.f. u.) per $10^{6}$ PBMCs. c-g PBMCs were stimulated with a spike peptide pool ( $\left.2 \mathrm{\mu g} / \mathrm{mL}\right)$ for $12 \mathrm{~h}$. Activation-induced markers (AIM) CD69 and 4-1BB were measured by flow cytometry. c Representative FACS plots showing the SARS-CoV-2-specific AIM ${ }^{+} \mathrm{CD}^{+} \mathrm{T}^{+}$cells. $\mathbf{d}$ Percentages of AIM ${ }^{+} \mathrm{CD} 8^{+} \mathrm{T}_{\text {cells }}$

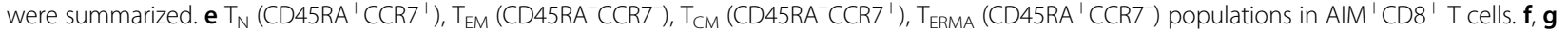
SARS-CoV-2-specific CD3 ${ }^{+} \mathrm{CD}^{-} \mathrm{CD}^{-}$(DN) T cells were identified by CD69 and 4-1BB after spike peptide pool stimulation. $\mathbf{h}$, i Intracellular cytokine staining assays were performed to confirm the presence of SARS-CoV-2-specific CD8 ${ }^{+} \mathrm{T}$ cells in PBMCs by measuring intracellular IFNy expression after peptide pool stimulation. Comparisons were done by Student's paired $t$-test in $\mathbf{b}$, $\mathbf{d}$, and $\mathbf{g}$, and one-way ANOVA corrected for multiple comparisons in i. ${ }^{* * *} P<0.0001 ;$ ns, not significant.

\section{A third dose of inactivated SARS-CoV-2 vaccine boosts immune responses in individuals with negative serologic responses to 2 doses}

The weakened or negative serological response has been noted in a small group of vaccinees who had no known immunodeficiency disease or were not in an immunecompromised condition. It is unclear whether these people are true "non-responders", and whether a third dose is necessary and beneficial as in immunecompromised patients ${ }^{28,29}$. In this study, we found NAbs were below the threshold in 9 participants after the primary 2-dose regimen. Of note, these participants have no known immunodeficiency diseases or are not in an immune-compromised condition. The level of NAbs in all of the nine participants increased rapidly within 1 week and reached the peak 2 weeks after the booster shot 

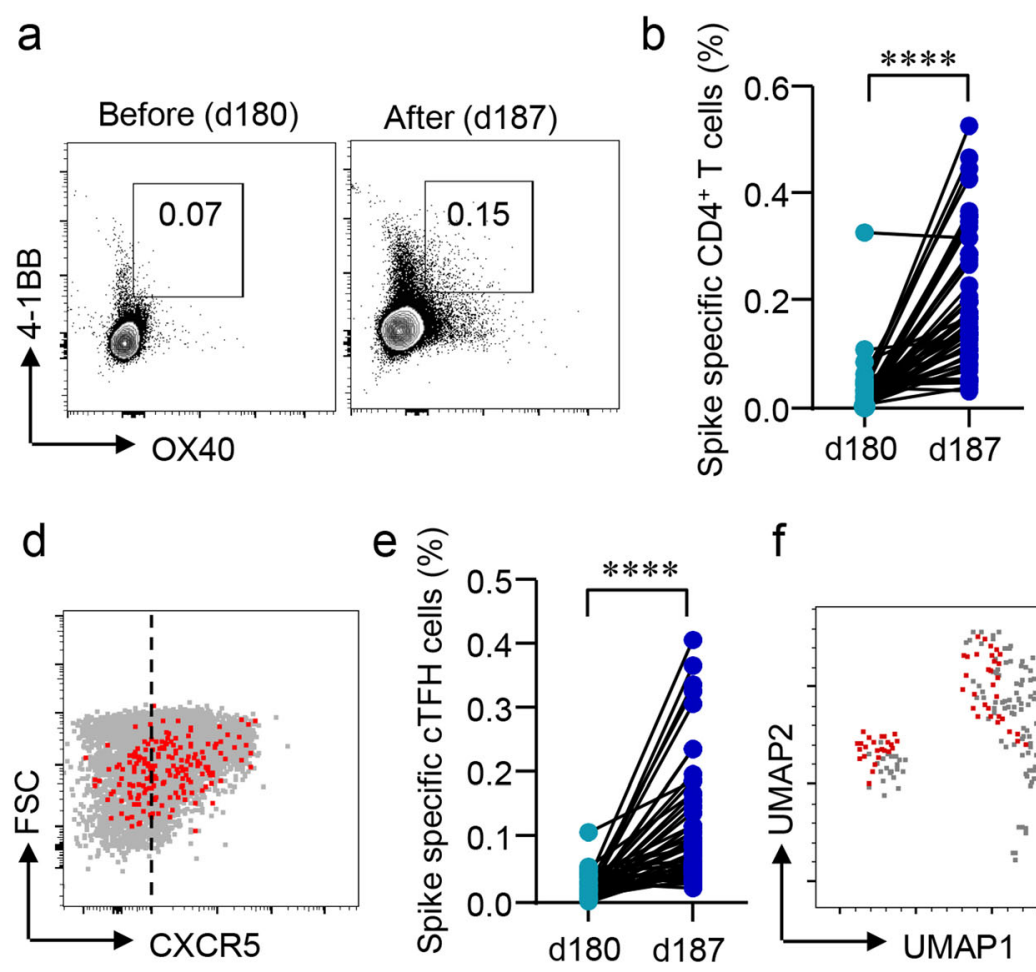

f

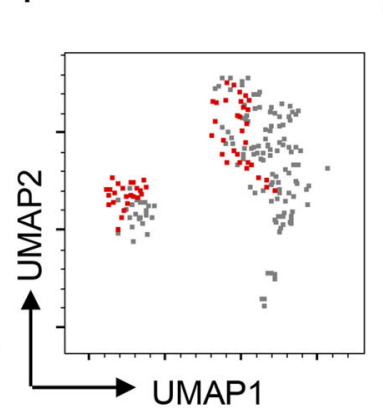

C

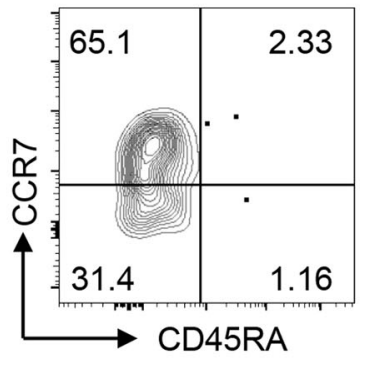

g

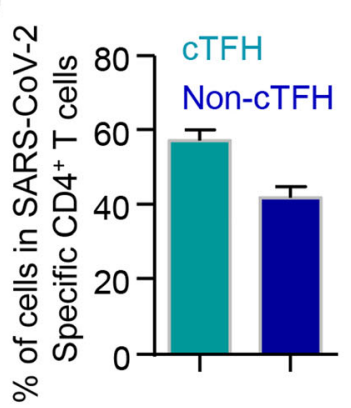

$\mathrm{h}$

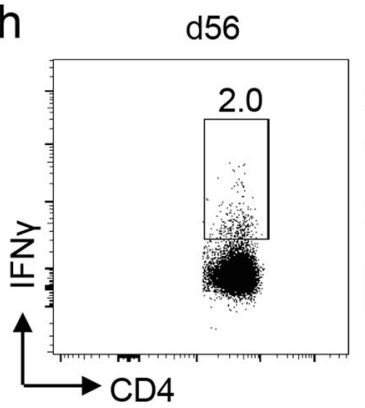

d180

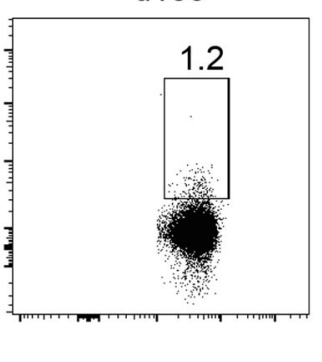

d187

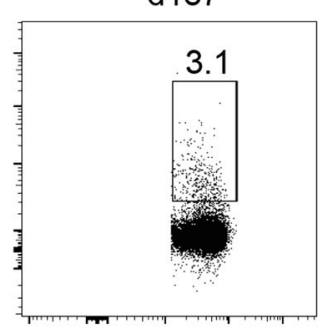

i

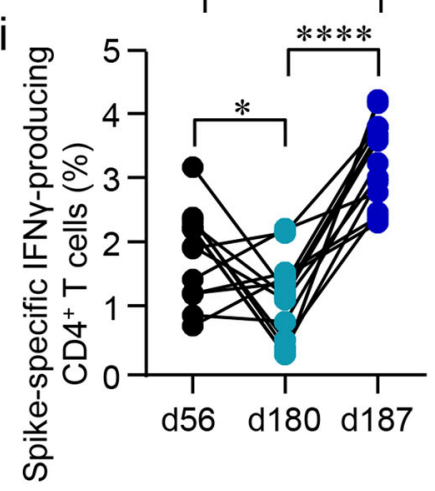

Fig. 4 Rapid induction of $\mathrm{CD}^{+}{ }^{+} \mathbf{T}$ cells by the third dose. $\mathbf{a}$, $\mathbf{b}$ Activation-induced markers (AIM) OX40 and 4-1BB in CD4 ${ }^{+} \mathrm{T}$ cells were detected after incubating PBMCs with spike peptide pool $(2 \mu \mathrm{g} / \mathrm{mL})$ for $12 \mathrm{~h}$. Percentages of $\mathrm{AIM}^{+} \mathrm{CD}^{+} \mathrm{T}$ cells in the PBMCs were summarized. $\mathbf{c} \mathrm{T}_{\mathrm{N}}$ $\left(C D 45 R^{+} C C R 7^{+}\right), T_{E M}\left(C D 45 R^{-} C C R 7^{-}\right), T_{C M}\left(C D 45 R A^{-} C C R 7^{+}\right), T_{E R M A}\left(C D 45 R A^{+} C C R 7^{-}\right)$populations in $\mathrm{AlM}^{+} \mathrm{CD}^{+} \mathrm{T}$ cells were gated. $\mathbf{d}$ Expression of CXCR5 in $\mathrm{AIM}^{+} \mathrm{CD}_{4}^{+} \mathrm{T}$ cells was measured by flow cytometry. e Percentages of circulating follicular helper $\mathrm{T}$ cells (CTFH) in total CD4 ${ }^{+} \mathrm{T}$ cells were summarized. $\mathbf{f}$ UMAP plot showed the distribution of cTFH cells among $\mathrm{AlM}^{+} \mathrm{CD} 4^{+} \mathrm{T}$ cells. $\mathbf{g}$ Percentage of cTFH cells in $\mathrm{AlM}^{+} \mathrm{CD} 4^{+} \mathrm{T}_{\mathrm{cells}}$. $\mathbf{h}$, $\mathbf{i}$ Intracellular cytokine staining assays were performed to confirm the presence of SARS-CoV-2-specific CD4 ${ }^{+}{ }^{T}$ cells in PBMCs by measuring intracellular IFNy expression after peptide pool stimulation. Comparisons were done by Student's paired $t$-test in $\mathbf{b}$, e and one-way ANOVA corrected for multiple comparison in $\mathbf{i} .{ }^{*} P<0.05,{ }^{* * *} P<0.001,{ }^{* * *} P<0.0001$.

(Fig. 5a), though NAbs levels in these nine participants were still significantly lower than others who were seropositive after the second dose (Fig. 5b).

The rapid recall of humoral responses indicated that the immune memory had been successfully established in these seronegative people after the second dose and persisted for at least 5 months. As expected, SARS-CoV-2specific memory B cells were indeed detected by labeling antigen-binding $\mathrm{B}$ cell receptor (BCR) in these individuals on d56 and d180. The percentage of SARS-CoV-2-specific memory B cells was quite stable over time between d56 and $\mathrm{d} 180$, and increased significantly after the third dose (Fig. 5c). ELISpot was next employed to identify functional memory B and T cells. Although no NAbs were detected at any time point before the third dose, spike- or RBD-specific IgG-secreting memory B cells were able to 

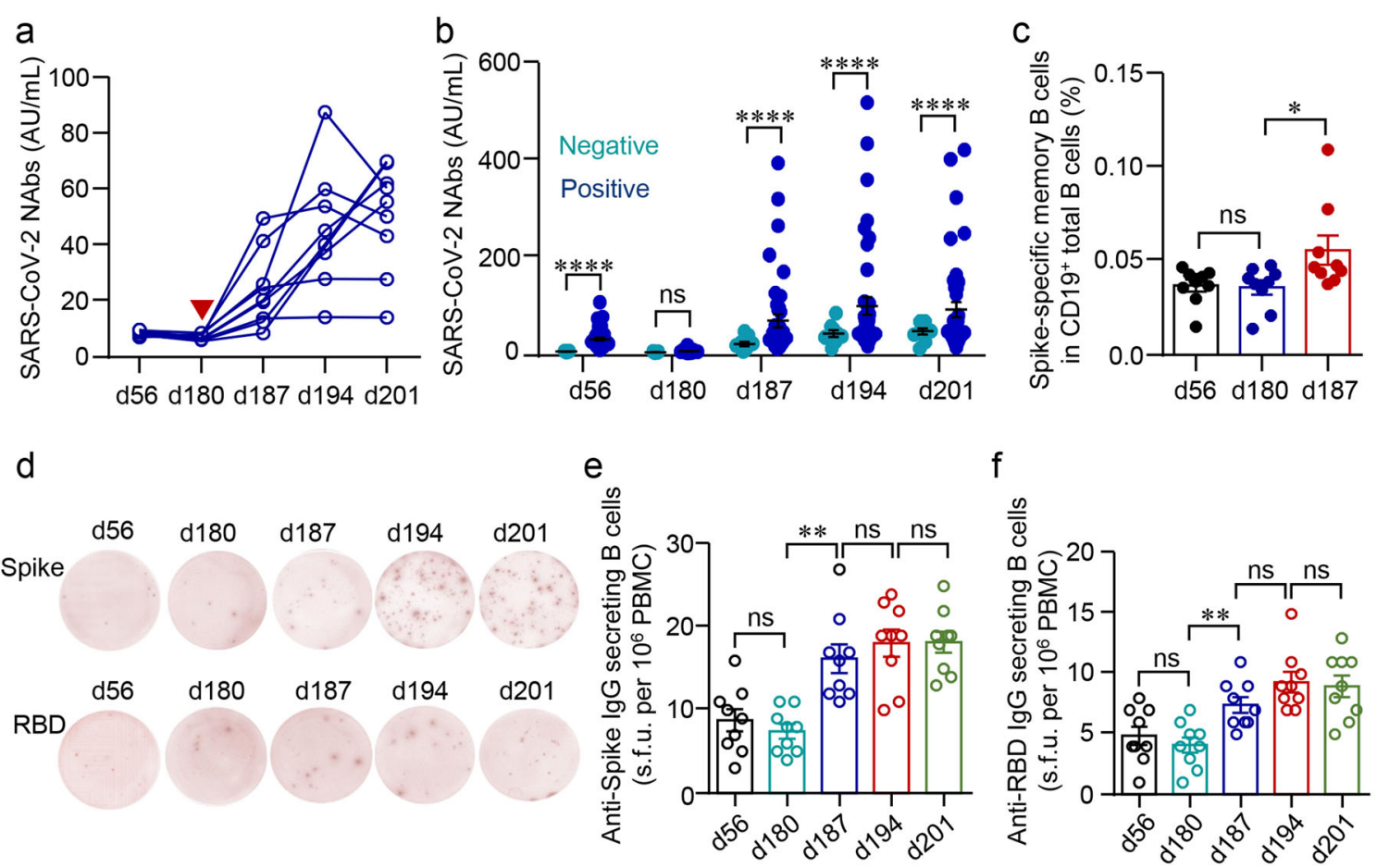

g

d56

IFNy

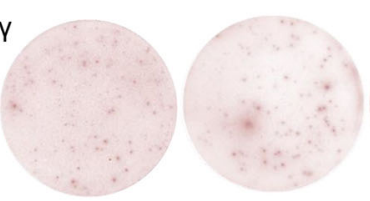

i

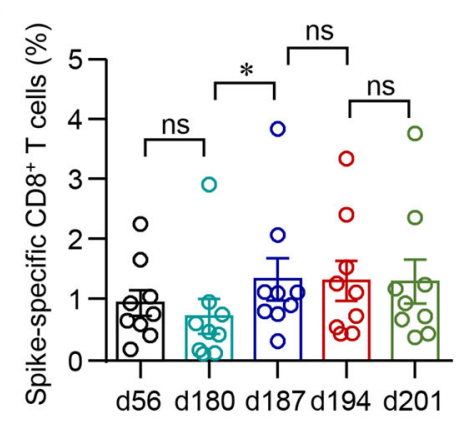

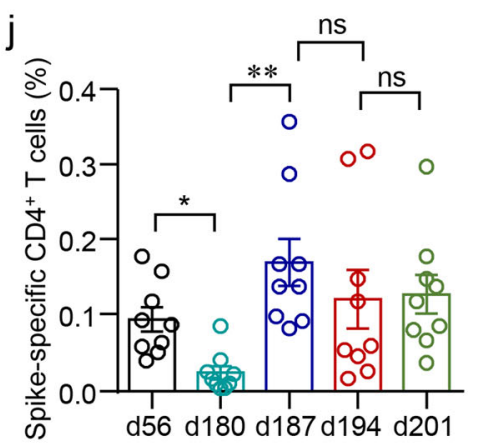

h

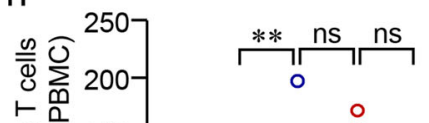

d201
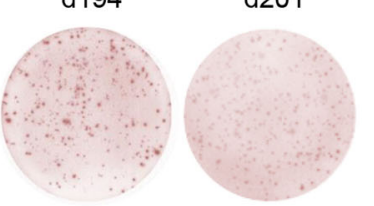

$\mathrm{k}$
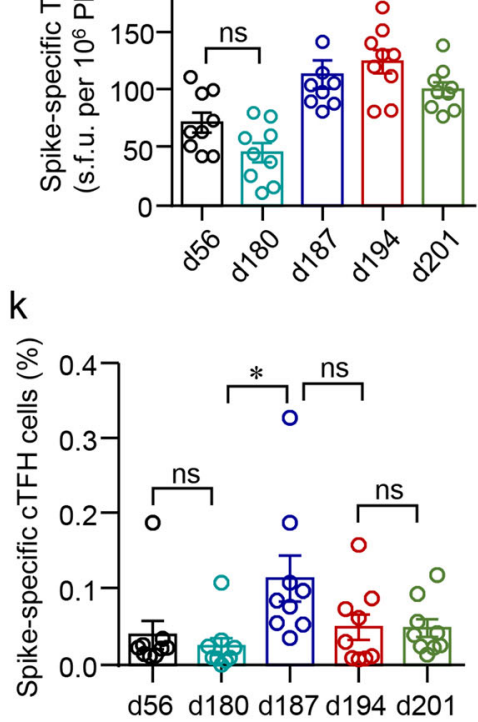

Fig. 5 Immune responses in HCWs with minimal serologic response to a standard two-dose vaccination schedule. a Serum NAbs in HCWs with minimal serologic response to a standard two-dose vaccination schedule were analyzed longitudinally at different time points before and after the third dose (red arrow). b Comparison of NAbs between vaccinees with negative or positive serological responses to a standard two-dose vaccination schedule. c Percentages of spike-specific memory B cells in HCWs with a negative serological response to a standard two-dose vaccination schedule. $\mathbf{d}-\mathbf{f}$ Numbers of spike- or RBD-specific lgG-producing B cells in HCWs with a negative serological response to a standard twodose vaccination schedule. $\mathbf{g}$, h Numbers of spike-specific IFNy-producing T cells as detected by ELISpot in HCWs with a negative serological

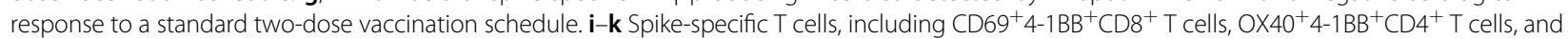
$\mathrm{CXCR5}{ }^{+} \mathrm{OX} 40^{+} 4-1 \mathrm{BB}^{+} \mathrm{CTFH}$ in HCWs with a negative serological response to a standard two-dose vaccination schedule. Comparisons were done by Wilcoxon rank-sum test in $\mathbf{b}$ and one-way ANOVA corrected for multiple comparisons in the rest panels. ${ }^{*} P<0.05,{ }^{* *} P<0.01,{ }^{* * * *} P<0.0001 ;$ ns, not significant. 
be detected by ELISpot on d 56 and maintained at a similar level till d180. The number increased within 1 week after the third dose and persisted thereafter (Fig. $5 \mathrm{~d}-\mathrm{f}$ ).

Spike-specific T cells were also detectable on d56 and d180 as measured by ELISpot, albeit with a downward trend (Fig. 5g, h). As expected, the third dose was capable of enhancing $\mathrm{T}$ cell responses in this population (Fig. $5 \mathrm{~h}$ ). The enhancement on SARS-CoV-2-specific $\mathrm{CD} 4^{+}$and $\mathrm{CD}^{+} \mathrm{T}$ cells by the third dose was further confirmed by measuring $\mathrm{AIM}^{+} \mathrm{T}$ cells $\left(\mathrm{OX} 40^{+} 4-1 \mathrm{BB}^{+}\right.$for $\mathrm{CD} 4^{+} \mathrm{T}$ cells and $\mathrm{CD} 9^{+} 4-1 \mathrm{BB}^{+}$for $\mathrm{CD} 8^{+} \mathrm{T}$ cells) by flow cytometry. Both spike-specific $\mathrm{CD} 4^{+} \mathrm{T}$ cells and $\mathrm{CD} 8^{+} \mathrm{T}$ cells were successfully expanded (Fig. 5i, j). We also observed the expansion of SARS-CoV-2-specific cTFH cells in these participants (Fig. 5k). Taken together, these results suggested that these participants were not true "no responders", and immune memory had been established but repeated antigen stimulations were needed.

\section{Discussion}

In this study, we investigated the duration of B cell and $\mathrm{T}$ cell immunity following the primary 2-dose vaccination regimen of the inactivated SARS-CoV-2 vaccine BBIBPCorV and the potential benefit of a third dose in a nonrandomized trial. Data in this study showed that NAbs gradually decreased after the second dose during a 5-month observation. SARS-CoV-2-specific B cells and $\mathrm{T}$ cells were detected and persisted in the peripheral blood 5 months after the second vaccination. Both humoral and cellular responses were rapidly and robustly elevated by the third dose of inactivated SARS-CoV-2 vaccine. The induction of both SARS-CoV-2-specific memory B cells and $\mathrm{T}$ cells by the inactivated vaccine supports durable protection, as has been shown in mRNA vaccines and other settings ${ }^{30,31}$. Another key observation in this study was the successful induction of antigen-specific memory B cell and $\mathrm{T}$ cell response in HCWs with low serological response to 2 doses of inactivation vaccines.

The titers of NAbs have been noted to decay following vaccination or SARS-CoV-2 infection ${ }^{32-34}$. However, HCWs who have recovered from COVID-19 show a substantially lower risk of reinfection with SARS-CoV- $2^{35}$. The number of RBD-specific memory B cells remained relatively stable between 6 and 12 months after SARSCoV-2 infection and BCR repertoire expanded markedly in these recovered patients after receiving an mRNA vaccine $^{36}$. Consistently, we found that spike- and RBDspecific memory B cells could still be detected in all COVID-19 convalescent patients up to 13 months after infection (Supplementary Fig. S6). SARS-CoV-2 mRNA vaccines were also capable of inducing sustained immune memory and long-term protecting effects ${ }^{30,37,38}$. Our study, together with these aforementioned studies, suggests that SARS-CoV-2-specific memory B cells may sustain longer than plasma cells. Prediction of vaccine efficacy should not solely rely on NAbs titers. Rather, memory B cells should be taken into account whenever it is possible.

Recently, a third dose of inactivated vaccine CoronaVac elicited a rapid and long-lasting recall antibody response with the capability of neutralizing several $\mathrm{VOCs}^{39}$. The rapid and strong secondary response by the inactivated vaccine represents a characteristic secondary immune response, which demonstrates the establishment of longterm immune memory within these participants. Our data confirm that SARS-CoV-2-specific memory B cells persisted 6 months after the primary vaccination and expanded substantially by a third dose of vaccine. The secondary immune response is one of the most important features of immune memory stimulated by vaccination, which is characterized by a faster and stronger immune response by memory $\mathrm{B}$ cells or plasma cells ${ }^{40}$. Despite the waning of antibodies, the generation of SARS-CoV-2specific memory B cells could mediate recall response in future infection and provide protective immunity. As has been observed in recovered COVID-19 patients, longlived bone marrow spike-binding plasma cells are quiescent $^{41}$, which explains the declining antibodies over time. Nonetheless, further investigation should be conducted on how waning immunity could affect protection against COVID-19.

Our data revealed that long-lasting memory B cells formed a basis for an enormous lift of serum NAbs after the third dose, not only against WT SARS-CoV-2 but also against B.1.617.2 Delta variant. As shown in Supplementary Fig. S1, the inactivated vaccine induced a broad spectrum of antibody responses to multiple structural proteins of the virus. Whether the lifted cross-reactive NAbs still targeted to RBD, or other domains of S protein, or even other proteins were involved, is an interesting question meriting further study.

Our study showed that SARS-CoV-2-specific $\mathrm{CD} 4^{+}$and $\mathrm{CD}^{+} \mathrm{T}$ cells in convalescent COVID-19 patients could persist up to 13 months (Supplementary Fig. S7). SARS$\mathrm{CoV}-2$-specific $\mathrm{CD} 4^{+}$and $\mathrm{CD}^{+}{ }^{+} \mathrm{T}$ cells induced by BBIBPCorV were detected in all the HCWs who received 2 doses of vaccine and last for at least 5 months. In line with previous data from an mRNA vaccine ${ }^{20}$, SARS-CoV-2-specific $\mathrm{CD} 4^{+} \mathrm{T}$ cells induced by inactivated vaccine mainly fall into central and effector memory subsets, while the majority of SARS-CoV-2-specific $\mathrm{CD}^{+} \mathrm{T}$ cells were $\mathrm{T}_{\text {EMRA }}$ cells. Because of the high CCR7 expression, the central memory $\mathrm{T}$ cells reside in the secondary lymphoid organs and readily expand upon infection or booster vaccination. Effector memory $\mathrm{T}$ cells circulate in between blood and peripheral tissues, providing prompt immune response at the early time point of infection ${ }^{42,43}$. For the emergence of VOCs of SARS-CoV-2, there is growing concern over vaccine 
efficacy. In addition, $\mathrm{T}$ cells from COVID-19 convalescents and in recipients of mRNA vaccine could recognize epitopes throughout the SARS-CoV-2 spike protein and the total reactivity against SARS-CoV-2 variants of B.1.1.7, B.1.351, P.1, and CAL.20 C lineages was mostly maintained in terms of magnitude and frequency of response ${ }^{44}$. SARSCoV-2-specific $\mathrm{T}$ cells from convalescent COVID-19 patients or vaccinated individuals targeted the conserved epitopes between prototype and VOCs ${ }^{45,46}$. Thus, SARSCoV-2-specific $T$ cells are less likely to be affected by antibody escapes mutations in VOCs. Moreover, the inactivated virus vaccine comprises all viral structural proteins. This means that more epitopes, especially those conserved epitopes in proteins other than spike are engaged as compared to mRNA or recombinant protein vaccines involving only RBD or spike. Ideally, a potent adjuvant rather than aluminum salts should be used to fully realize this advantage.

Another interesting finding of this study was the induction of SARS-CoV-2-specific cTFH cells by the inactivated vaccine. Our previous study has demonstrated the mobilization of cTFH cells after the first dose of inactivated vaccination ${ }^{11}$. For the relatively late development of humoral response by the inactivated vaccines, early response of cTFH cells could contribute to the early protection of vaccination when antibody level was still low $^{3,47}$. cTFH cells have been associated with humoral response in COVID-19 patients or vaccination individuals ${ }^{20,23}$. Data in this study further confirmed that the induction of cTFH cells by the inactivated vaccine correlated with humoral response closely.

A third dose of the SARS-CoV-2 vaccine may be particularly in need for the immunocompromised population. Low seroconversion rates to mRNA vaccination have been reported in solid transplant recipients ${ }^{48}$. The applications of immune suppressants or B cell-targeted therapies could also hamper serological response to vaccination ${ }^{49,50}$. Recently, data show that antibody response was enhanced in kidney transplant recipients with minimal serologic response to two doses by a third dose of mRNA vaccine ${ }^{28}$. In this study, we found that a group of healthy individuals were not mounted with detectable NAbs by two doses of vaccination. However, memory $\mathrm{B}$ and $\mathrm{T}$ cells could be detected 5 months after the second immunization. The third dose of inactivated vaccine could induce an elevated level of NAbs and an extensive expansion of memory cells within 1 week, suggesting that the memory response could also be effectively recalled upon SARS-CoV-2 infection. Therefore, these individuals were not true "non-responders" but already equipped with immune memory that may at least confer protection against severe diseases. Nevertheless, it should be noted that further studies are needed to confirm the relevance between these memory responses and protection. Moreover, a third dose is necessary to further secure the protection.
In conclusion, our study revealed sustained memory B and $\mathrm{T}$ cell responses after a standard two-dose vaccination regimen of inactivated vaccines. Immune responses against SARS-CoV-2 were readily recalled and further elevated by a third dose of the inactivated vaccine, which is especially beneficial for individuals facing high exposure risks, such as HCWs, and has been demonstrated to be safe and effective in our study and others ${ }^{28,51}$.

\section{Materials and methods \\ Human subjects}

In this study, we conducted a nonrandomized trial and recruited participants from a prospective cohort at the First Affiliated Hospital of Sun Yat-sen University in Guangzhou, Guangdong, China. As we described previously ${ }^{11}, 63 \mathrm{HCWs}$ received the inactivated SARS-CoV-2 vaccine BBIBP-CorV (BBIBP-CorV, Sinopharm, Beijing) in the morning (9 am-11 am) or afternoon (3 pm-5 pm) on $\mathrm{d} 0$ and $\mathrm{d} 28$, respectively. Fifty of the $63 \mathrm{HCWs}$ were volunteered to receive a third booster shot of the inactivated vaccine 6 months after the prime vaccination (d180). They were assigned to the morning or afternoon group as to their previous vaccinating time accordingly. Demographic characteristics of the HCWs were summarized in Supplementary Table S1. Blood samples were collected on d180 before the booster dose and d187, d194, and d208 after the booster dose. Convalescent patients who had recovered from SARS$\mathrm{CoV}-2$ infection were recruited as the positive control (Supplementary Table S2). All studies were approved by the Institutional Review Board of the First Affiliated Hospital of Sun Yat-sen University and written consent was obtained from all participants. The prospective cohort and the trial were registered to the Chinese Clinical Trial Registry (ChiCTR2100042222 and ChiCTR2100048665).

\section{Cell isolation}

Blood samples were collected into the heparinized tubes and processed right after sample collection. PBMCs were isolated using density-gradient centrifugation. Briefly, blood samples were diluted with PBS at a 1:1 ratio and loaded on top of Lymphoprep ${ }^{\mathrm{TM}}$ (StemCell) in the Falcon tubes. The falcon tubes were then centrifuged at $1500 \mathrm{rpm}$ for $30 \mathrm{~min}$. The medium layer was collected and washed with PBS twice. PBMCs were cryopreserved in Bambanker (StemCell) immediately.

\section{SARS-CoV-2 NAb measurement}

A one-step competitive Chemiluminescent immunoassay was used to detect the concentration of NAbs against SARS-CoV-2 in sera by iFlash 2019-nCoV NAb kit (YHLO Biotech Co, Ltd) as previously reported ${ }^{25}$. In this assay, the RBD of the SARS-CoV-2 was coated on magnetic beads. Acridinium ester-labeled ACE2 was designed to compete with SARS-CoV-2 NAbs in sera for the RBD. 
NAbs titers were calculated by an iFlash3000 Chemiluminescence Immunoassay Analyzer (YHLO Biotech Co, Ltd). Neutralizing activity is determined in arbitrary units (AU) and the cut-off is $10 \mathrm{AU} / \mathrm{mL}$.

\section{Ex vivo ELISpot assay}

IFN $\gamma$ ELISpot assays were performed as described previously ${ }^{27}$. Briefly, $100 \mu \mathrm{L}$ of the coating antibody $(15 \mu \mathrm{g} /$ $\mathrm{mL}$, MabTech, \#3420-3-250) was added to the well of ELISpot plate (MabTech) and incubated overnight at $4{ }^{\circ} \mathrm{C}$. The peptide pool of SARS-CoV-2 spike protein (MabTech, \#3630-1) was added to 300,000 PBMCs per test at a final concentration of $2 \mu \mathrm{g} / \mathrm{mL}$ for $24 \mathrm{~h}$. Unstimulated cells were used as negative control while anti-CD3/CD28 dynabeads (Thermo Fisher) stimulated cells were set as the positive control. Plates were incubated with IFNY detection antibody $(1 \mu \mathrm{g} / \mathrm{mL}$, MabTech, \#3420-6-250), followed by Avidin-HRP ( $1 \mu \mathrm{g} / \mathrm{mL}$, Vector, \#A-2004-5) and visualized using the ACE substrate. Antigen-specific $\mathrm{T}$ cell responses were quantified by subtracting the number of spots in unstimulated cells from the peptide stimulated cells.

SARS-CoV-2-specific B cell ELISpot was performed as previously described ${ }^{41}$. Briefly, ELISpot plates were coated with $10 \mathrm{ug} / \mathrm{mL}$ recombinant RBD protein (Sino Biological, \#40592-VNAH-100) and $8 \mathrm{ug} / \mathrm{mL}$ spike protein (Sino Biological, \#40589-V08B1) overnight at $4{ }^{\circ} \mathrm{C}$. To optimize the human IgG B cell ELISpot assay, PBMCs were cultured with a mixture of R848 $(1 \mu \mathrm{g} / \mathrm{mL}$, Tocris, $\# 4536 / 10)$ and IL-2 (20 ng/mL, PeproTech, \#200-02-10) for 3 days to secrete a detectable amount of antibody ${ }^{52,53}$. After prestimulation, cells were washed extensively to remove secreted antibodies. 500,000 PBMCs were added to the coated plates and incubated for $18 \mathrm{~h}$ at $37^{\circ} \mathrm{C}$ with $5 \%$ $\mathrm{CO}_{2}$. The following day, cells were removed and plates were incubated with Biotin-anti-Human IgG $(1 \mu \mathrm{g} / \mathrm{mL}$, Jackson ImmunoResearch, \#709-065-098). Plates were then incubated with Avidin-HRP followed by visualization with ACE substrate. ELISpot plates were analyzed using an ELISpot counter (Cellular Technologies Ltd). Results were expressed as s.f.u. per $10^{6}$ PBMCs. Responses were considered positive if the results were at least three times the mean of the negative control wells and $>25$ s.f.u. per $10^{6}$ PBMCs. Data were excluded when negative control wells had $>30$ s.f.u. per $10^{6}$ PBMCs or positive control wells (anti-CD3/CD28 dynabeads) had no spot.

\section{Detection of SARS-CoV-2-specific T cells}

PBMCs were cultured in RPMI 1640 supplemented with $10 \% \mathrm{FBS}$ and $1 \%$ penicillin and streptomycin (Thermo Fisher) at $37^{\circ} \mathrm{C}$ overnight. The cells were then cultured with or without the peptide pool of SARS-CoV-2 spike protein $(2 \mu \mathrm{g} / \mathrm{mL})$ for $12 \mathrm{~h}$. An equal concentration of DMSO in PBS was used as the negative control. Antigen- specific $\mathrm{T}$ cells were measured as a percentage of $\mathrm{AIM}^{+}$ $\left(\mathrm{OX} 40^{+} \mathrm{CD} 137^{+}\right)$for $\mathrm{CD}^{+} \mathrm{T}$ or $\left(\mathrm{CD} 69^{+} \mathrm{CD} 137^{+}\right)$for $\mathrm{CD}^{+}{ }^{+}$cells after stimulation of PBMCs with the peptide pool of spike protein ${ }^{27}$. After the stimulation, cells were first stained with Zombie Red for dead cell exclusion. Cells were then stained with anti-CD3-Pacific blue, antiCD4-BV510, anti-CD8-Percp, anti-CD69-Super Bright 436, anti-CD134 (OX40)-BV605, and anti-CD137-(41BB)-PE antibodies for antigen-specific $T$ cell analysis. As for phenotype analysis of SARS-CoV-2-specific $\mathrm{T}$ cells, cells were further labeled with anti-CCR7-APC/cy7, antiCD45RA-BV650, anti-CXCR5-BV711, and anti-PD-1-PE/ cy7 antibodies. All FACS antibodies were purchased from Biolegend. Stimulation with anti-CD3/CD28 dynabeads was included as positive controls. Any sample with a low response to anti-CD3/CD28 stimulation was excluded as quality control for the samples. Data were acquired by flow cytometry.

\section{Detection of SARS-CoV-2-specific memory B cells}

SARS-CoV-2-specific memory B cells were detected as we described previously ${ }^{11}$. First, biotinylated antigens were multimerized with fluorescence-labeled streptavidin individually. Recombinant spike protein (R\&D, \#BT10549-050) was mixed with BV510-streptavidin (BioLegend) at 10:1 ratio and BV785-streptavidin (BioLegend) at 18:1 ratio at $4{ }^{\circ} \mathrm{C}$ for $1 \mathrm{~h}$. Recombinant RBD protein (R\&D, \#BT10500050) was mixed with BV421-streptavidin (BioLegend) at 20:1 ratio at $4{ }^{\circ} \mathrm{C}$ for $1 \mathrm{~h}$. The antigen probes prepared above were then mixed in $50 \mathrm{mM}$ free d-biotin (Macklin) in PBS to ensure minimal cross-reactivity. PBMCs were thawed and let to rest at $37^{\circ} \mathrm{C}$ with $5 \% \mathrm{CO}_{2}$ for $2 \mathrm{~h}$ and stained with Zombie Red (BioLegend) in PBS at room temperature for $20 \mathrm{~min}$. Cells were then stained with $50 \mu \mathrm{L}$ of antigen probe cocktail containing $100 \mathrm{ng}$ of spike and $50 \mathrm{ng}$ of RBD at $4{ }^{\circ} \mathrm{C}$ for $30 \mathrm{~min}$. Cells were washed with PBS and then stained with the following antibody cocktail: anti-CD3-Pacific Blue $^{\mathrm{TM}}$, anti-CD19-PE-CY7, anti-CD27-AF700, anti-IgDFITC, anti-CD38-BV650, anti-IgM-BV605, anti-IgG-AF647, anti-IgA-PE all from BioLegend at 1:100 dilution. Samples were acquired by flow cytometry.

\section{Detection of SARS-CoV-2-specific IFNY-producing T cells}

The detection of spike-reactive $T$ cells was performed as described with modification ${ }^{54}$. Briefly, overnight-rested PBMCs were cultured with or without the peptide pool of SARS-CoV-2 spike protein $(4 \mu \mathrm{g} / \mathrm{mL})$ in the presence of $3 \mu \mathrm{g} / \mathrm{mL}$ of anti-CD28 monoclonal antibodies for $24 \mathrm{~h}$. Cells were then incubated with Brefeldin A for an additional $5 \mathrm{~h}$. Cells were stained with anti-CD3-Pacific blue, anti-CD4BV510, anti-CD8-Percp antibodies for surface markers. Cells were then washed, fixed with Cytofix/Cytoperm, and stained with anti-IFN $\gamma$-PE-Cy7 (BioLegend). Dead cells were excluded by Zombie Red staining. Samples were 
analyzed by flow cytometry. Samples without peptide stimulation were used as the negative control.

\section{Flow cytometry}

All flow cytometry samples were analyzed using cryopreserved cells which were thawed and suspended in RPMI 1640 media supplemented with 2\% FBS. All samples were analyzed by flow cytometry with Cytek $^{\mathrm{TM}}$ AURORA. FlowJo (Tree Star, USA) software was used for FACS data analysis. Details of antibodies used in this study are listed in Supplementary Table S3.

\section{ELISA-based antibody-antigen distribution analysis}

All SARS-CoV-2 proteins were purchased from Sino Biological (Beijing, China). About $200 \mathrm{ng} /$ well of SARSCoV-2 spike (\#40589-V08B1), spike S1 subunit (\#40591V08H), spike NTD (\#40591-V49H), spike S2 subunit (\#40590-V08B), RBD (\#40592-V08H), RBD T478K (\#40592V08H91), nucleocapsid (\#40588-V08B), and envelope (\#40609-V10E3) were coated on the 96-well ELISA plate overnight at $4{ }^{\circ} \mathrm{C}$, respectively. Plates were washed by PBS supplemented with $0.05 \%$ Tween-20 (PBST) three times, followed by blocking with 5\% BSA in PBST for $1 \mathrm{~h}$ at room temperature. Sera were diluted 20-fold for the first well and fourfold serial diluted for subsequent wells in 5\% BSA in PBST and incubated at $4{ }^{\circ} \mathrm{C}$ overnight. Plates were washed three times by PBST and added with HRP-conjugated goat anti-human IgG antibody (\#2040-05, SouthernBiotech, 1:3000) for $30 \mathrm{~min}$ at room temperature. Plates were washed five times with PBST. 3,3',5,5'-Tetramethylbenzidine (TMB) substrate (\#P0209, Beyotime) was added for $15 \mathrm{~min}$ and stopped by the stopping buffer (\#C1058, Solarbio). OD450 was measured by Varioskan Lux Microplate Reader (Thermo Fisher).

\section{Pseudovirus neutralizing assay}

For the generation of SARS-CoV-2-Spike (Wuhan-Hu-1) pseudovirus $^{55}$, pcDNA3.1-2019-nCoV-Spike and pNL4$3 \mathrm{R}^{-} \mathrm{E}^{-}$(gifts from Dr. Lu Lu, Fudan University) were cotransfected to HEK293T with Lipo8000 (\#C0533, Beyotime) according to the manufacturer's instruction. For the generation of the B.1.617.2 Delta-variant spike pseudovirus, pCMV3-SARS-CoV-2-Spike (\#VG40804-UT, Sino Biological), pSPAX2 and pLenti-CMV-Luc-puro were cotransfected to HEK293T. The pseudovirus was harvested $72 \mathrm{~h}$ post-transfection and stored at $-80^{\circ} \mathrm{C}$ until use. About $2 \times 10^{4}$ hACE2-293T/well were seeded on the black flatbottom 96-well plate (\#655090, Greiner Bio-one) for $16 \mathrm{~h}$ in advance. Sera were diluted tenfold for the first well and fourfold serial diluted for subsequent wells in Dulbecco's Modified Eagle Medium, then co-incubated with pseudovirus at $37^{\circ} \mathrm{C}$ for $1 \mathrm{~h}$. Then the co-incubated samples, together with samples without sera or pseudovirus as controls, were subjected with $10 \mu \mathrm{g} / \mathrm{mL}$ polybrene (\#C0351, Beyotime) to the hACE2-293T for 6-h absorption, followed by replacement of the culture medium for the next $42 \mathrm{~h}$ incubation at $37^{\circ} \mathrm{C}, 5 \% \mathrm{CO}_{2}$. Infected cells were processed to the luciferase assay using the Luciferase Assay System (\#E4550, Promega). The illuminescence was measured by Varioskan Lux Microplate Reader (Thermo Fisher). The $\mathrm{ID}_{50}$ values were determined by a four-parameter nonlinear regression curve (GraphPad Prism).

\section{Statistical analysis}

Statistical analysis was performed using Prism 7. Comparisons were assessed using Wilcoxon rank-sum test, Student's $t$-test, paired Student's $t$-test, or one-way ANOVA followed by Bonferroni's multiple comparison post-test as appropriate. $P$ values $<0.05$ were considered statistically significant.

\section{Acknowledgements}

We thank Prof. Lu Lu at Fudan University for his kind help in pseudovirus assays. The work is supported by the Talent Program of the First Affiliated Hospital, Sun Yat-sen University (Y70311), the Hundred Talent Program of Sun Yat-sen University (Y61229), and the Science and Technology Program of Guangzhou (202103000076).

\section{Author details}

${ }^{1}$ Department of Endocrinology, The First Affiliated Hospital of Sun Yat-sen University, Guangzhou, Guangdong, China. ${ }^{2}$ Clinical Trials Unit, The First Affiliated Hospital of Sun Yat-sen University, Guangzhou, Guangdong, China. ${ }^{3}$ Institute of Precision Medicine, The First Affiliated Hospital of Sun Yat-sen University, Guangzhou, Guangdong, China. ${ }^{4}$ Department of Rheumatology and Clinical Immunology, The First Affiliated Hospital of Sun Yat-sen University, Guangzhou, Guangdong, China. ${ }^{5}$ Department of Laboratory Medicine, The First Affiliated Hospital of Sun Yat-sen University, Guangzhou, Guangdong, China. ${ }^{6}$ Department of Medical Affairs, The First Affiliated Hospital of Sun Yat-sen University, Guangzhou, Guangdong, China

\section{Author contributions}

$H X, H Z$, and JW supervised the study. $Y L, Q$ Zeng, $C D, M L, L L$, and $D L$ contributed equally to the study. HX, HZ, JW, and YL conceived and designed the study. YL, DL, JM, and RM recruited participants in the trial and collected blood samples. Q Zeng, CD, ML, LL, Ming Liu, and XR performed the experiments and collected data. Q Zeng and Q Zhou performed statistical analysis. $\mathrm{HZ}, \mathrm{YL}, \mathrm{Q}$ Zeng, $C D, \mathrm{ML}, \mathrm{LL}$, and $\mathrm{DL}$ drafted the report. $\mathrm{HX}$, JW, SP, and Min Liu made critical revisions to the manuscript. All authors contributed to the interpretation of data. All authors approved the final version before submission.

\section{Data availability}

All data from this study are included within this manuscript/Supplementary Material and are available from the Lead Contact (Haipeng Xiao, xiaohp@mail. sysu.edu.cn) upon request.

\section{Conflict of interest}

The authors declare no competing interests.

\section{Publisher's note}

Springer Nature remains neutral with regard to jurisdictional claims in published maps and institutional affiliations.

Supplementary information The online version contains supplementary material available at https://doi.org/10.1038/s41421-022-00373-7.

Received: 20 September 2021 Accepted: 27 December 2021

Published online: 01 February 2022 


\section{References}

1. Crook, H., Raza, S., Nowell, J., Young, M. \& Edison, P. Long covid-mechanisms, risk factors, and management. BMJ 374, n1648 (2021).

2. COVID-19 Map - Johns Hopkins Coronavirus Resource Center. https:// coronavirus.jhu.edu/map.html (2021).

3. Xia, S. et al. Safety and immunogenicity of an inactivated SARS-CoV-2 vaccine, BBIBP-CorV: a randomised, double-blind, placebo-controlled, phase 1/2 trial. Lancet Infect. Dis. 21, 39-51 (2021).

4. Jackson, L. A. et al. An mRNA vaccine against SARS-CoV-2 - Preliminary report. N. Engl. J. Med. 383, 1920-1931 (2020).

5. Krause, P. R. \& Gruber, M. F. Emergency use authorization of covid vaccines Safety and efficacy follow-up considerations. N. Engl. J. Med. 383, e107 (2020)

6. Khoury, D. S. et al. Neutralizing antibody levels are highly predictive of immune protection from symptomatic SARS-CoV-2 infection. Nat. Med. 27, 1205-1211 (2021).

7. Krammer, F. A correlate of protection for SARS-CoV-2 vaccines is urgently needed. Nat. Med. 27, 1147-1148 (2021).

8. Walls, A. C. et al. Structure, function, and antigenicity of the SARS-CoV-2 spike glycoprotein. Cell 181, 281-292 (2020). e286.

9. Goel, R. R. et al. Distinct antibody and memory B cell responses in SARS-CoV-2 naive and recovered individuals following mRNA vaccination. Sci. Immunol. 6 eabi6950 (2021)

10. Xia, S. et al. Effect of an inactivated vaccine against SARS-CoV-2 on safety and immunogenicity outcomes: interim analysis of 2 randomized clinical trials. JAMA 324, 951-960 (2020).

11. Zhang, $\mathrm{H}$. et al. Time of day influences immune response to an inactivated vaccine against SARS-CoV-2. Cell Res. 31, 1215-1217 (2021).

12. Marot, S. et al. Rapid decline of neutralizing antibodies against SARS-CoV-2 among infected healthcare workers. Nat. Commun. 12, 844 (2021).

13. Shrotri, M. et al. Spike-antibody waning after second dose of BNT162b2 or ChAdOx1. Lancet 398, 385-387 (2021).

14. Krause, P. R. et al. SARS-CoV-2 variants and vaccines. N. Engl. J. Med. $\mathbf{3 8 5}$ 179-186 (2021).

15. Pegu, A. et al. Durability of mRNA-1273 vaccine-induced antibodies against SARS-CoV-2 variants. Science 373, 1372-1377 (2021).

16. Soresina, A. et al. Two X-linked agammaglobulinemia patients develop pneumonia as COVID-19 manifestation but recover. Pediatr. Allergy Immunol. 31, 565-569 (2020).

17. Wurm, H. et al. Recovery from COVID-19 in a B-cell-depleted multiple sclerosis patient. Mult. Scler. 26, 1261-1264 (2020).

18. Oberhardt, V. et al. Rapid and stable mobilization of CD8 ${ }^{+} \mathrm{T}$ cells by SARS-CoV2 mRNA vaccine. Nature 597, 268-273 (2021).

19. Kared, $\mathrm{H}$. et al. SARS-CoV-2-specific $\mathrm{CD}^{+} \mathrm{T}$ cell responses in convalescent COVID-19 individuals. J. Clin. Invest. 131, e145476 (2021).

20. Painter, M. M. et al. Rapid induction of antigen-specific CD4 ${ }^{+} \mathrm{T}$ cells is associated with coordinated humoral and cellular immunity to SARS-CoV-2 mRNA vaccination. Immunity 54, 2133-2142 (2021).

21. Crotty, S. Follicular helper CD4 T cells (TFH). Annu. Rev. Immunol. 29, 621-663 (2011).

22. Boppana, S. et al. SARS-CoV-2-specific circulating T follicular helper cells correlate with neutralizing antibodies and increase during early convalescence. PLOS Pathog. 17, e1009761 (2021).

23. Juno, J. A. et al. Humoral and circulating follicular helper $\mathrm{T}$ cell responses in recovered patients with COVID-19. Nat. Med. 26, 1428-1434 (2020).

24. Deng, Y., Li, Y., Yang, R. \& Tan, W. SARS-CoV-2-specific T cell immunity to structural proteins in inactivated COVID-19 vaccine recipients. Cell Mol. Immunol. 18, 2040-2041 (2021).

25. Tenbusch, M. et al. Heterologous prime-boost vaccination with ChAdOx1 nCoV-19 and BNT162b2. Lancet Infect. Dis. 21, 1212-1213 (2021).

26. Tea, F. et al. SARS-CoV-2 neutralizing antibodies: Longevity, breadth, and evasion by emerging viral variants. PLOS Med. 18, e1003656 (2021).

27. Dan, J. M. et al. Immunological memory to SARS-CoV-2 assessed for up to 8 months after infection. Science 371, eabf4063 (2021).

28. Benotmane, I. et al. Antibody response after a third dose of the mRNA-1273 SARS-CoV-2 vaccine in kidney transplant recipients with minimal serologic response to 2 doses. JAMA 326, 1063-1065 (2021).

29. Hall, V. G. et al. Randomized trial of a third dose of mRNA-1273 vaccine in transplant recipients. N. Engl. J. Med. 385, 1244-1246 (2021).

30. Goel, R. R. et al. mRNA vaccines induce durable immune memory to SARSCoV-2 and variants of concern. Science 374, abm0829 (2021).
31. Akondy, R. S. et al. Origin and differentiation of human memory CD8 T cells after vaccination. Nature 552, 362-367 (2017).

32. Israel, A. et al. Large-scale study of antibody titer decay following BNT162b2 mRNA vaccine or SARS-CoV-2 infection. medRxiv https:/pubmed.ncbi.nlm.nih. gov/34462761 (2021).

33. Long, Q. X. et al. Clinical and immunological assessment of asymptomatic SARS-CoV-2 infections. Nat. Med. 26, 1200-1204 (2020).

34. Ibarrondo, F. J. et al. Rapid decay of anti-SARS-CoV-2 antibodies in persons with mild Covid-19. N. Engl. J. Med. 383, 1085-1087 (2020).

35. Hall, V. J. et al. SARS-CoV-2 infection rates of antibody-positive compared with antibody-negative health-care workers in England: a large, multicentre, prospective cohort study (SIREN). Lancet 397, 1459-1469 (2021).

36. Wang, Z. et al. Naturally enhanced neutralizing breadth against SARS-CoV-2 one year after infection. Nature 595, 426-431 (2021).

37. Doria-Rose, N. et al. Antibody persistence through 6 months after the second dose of mRNA-1273 vaccine for Covid-19. N. Engl. J. Med. 384, 2259-2261 (2021).

38. Tenforde, M. W. et al. Sustained effectiveness of Pfizer-BioNTech and Moderna vaccines against COVID-19 associated hospitalizations among adults - United States, March-July 2021. Morb. Mortal. Wkly. Rep. 70, 1156-1162 (2021).

39. Kang, W. et al. A third dose of inactivated vaccine augments the potency, breadth, and duration of anamnestic responses against SARS-CoV-2. medRxiv https://www.medrxiv.org/content/10.1101/2021.09.02.21261735v1 (2021).

40. Quast, I. \& Tarlinton, D. B cell memory: understanding COVID-19. Immunity 54 205-210 (2021).

41. Turner, J. S. et al. SARS-CoV-2 infection induces long-lived bone A third dose of inactivated vaccine 1 augments the potency, breadth, and duration of anamnestic responses against SARS-CoV-2.marrow plasma cells in humans. Nature 595, 421-425 (2021).

42. Kaech, S. M., Wherry, E. J. \& Ahmed, R. Effector and memory T-cell differentiation: implications for vaccine development. Nat. Rev. Immunol. 2, 251-262 (2002).

43. Sallusto, F., Geginat, J. \& Lanzavecchia, A. Central memory and effector memory T cell subsets: function, generation, and maintenance. Annu Rev. Immunol. 22, 745-763 (2004).

44. Tarke, A. et al. Impact of SARS-CoV-2 variants on the total CD4 ${ }^{+}$and $C D 8^{+} \mathrm{T}$ cell reactivity in infected or vaccinated individuals. Cell Rep. Med. 2, 100355 (2021).

45. Skelly, D. T. et al. Two doses of SARS-CoV-2 vaccination induce robust immune responses to emerging SARS-CoV-2 variants of concern. Nat. Commun. 12, 5061 (2021).

46. Redd, A. D. et al. CD8 ${ }^{+}$T-cell responses in COVID-19 convalescent individuals target conserved epitopes from multiple prominent SARS-CoV-2 circulating variants. Open Forum Infect. Dis. 8, ofab143 (2021)

47. Al Kaabi, N. et al. Effect of 2 inactivated SARS-CoV-2 vaccines on symptomatic COVID-19 infection in adults: a randomized clinical trial. JAMA 326, 35-45 (2021).

48. Boyarsky, B. J. et al. Antibody response to 2-dose SARS-CoV-2 mRNA vaccine series in solid organ transplant recipients. JAMA $\mathbf{3 2 5}$, 2204-2206 (2021).

49. Haberman, R. H. et al. Methotrexate hampers immunogenicity to BNT162b2 mRNA COVID-19 vaccine in immune-mediated inflammatory disease. Ann Rheum. Dis. 80, 1339-1344 (2021).

50. Mrak, D. et al. SARS-CoV-2 vaccination in rituximab-treated patients: B cells promote humoral immune responses in the presence of T-cell-mediated immunity. Ann. Rheum. Dis. 80, 1345-1350 (2021).

51. Kamar, N. et al. Three doses of an mRNA Covid-19 vaccine in solid-organ transplant recipients. N. Engl. J. Med. 385, 661-662 (2021).

52. Jahnmatz, M. et al. Optimization of a human lgG B-cell ELISpot assay for the analysis of vaccine-induced B-cell responses. J. Immunol. Methods 391, 50-59 (2013).

53. Long, Q. X. et al. Immune memory in convalescent patients with asymptomatic or mild COVID-19. Cell Discov. 7, 18 (2021).

54. Peng, $Y$. et al. Broad and strong memory $\mathrm{CD}^{+}$and $\mathrm{CD}^{+} \mathrm{T}$ cells induced by SARS-CoV-2 in UK convalescent individuals following COVID-19. Nat. Immunol. 21, 1336-1345 (2020).

55. Xia, S. et al. Inhibition of SARS-CoV-2 (previously 2019-nCoV) infection by a highly potent pan-coronavirus fusion inhibitor targeting its spike protein that harbors a high capacity to mediate membrane fusion. Cell Res. 30, 343-355 (2020). 